\title{
Review
}

Neuropsychobiology

\section{Pharmaco-EEG Studies in Animals: A History-Based Introduction to Contemporary Translational Applications}

\author{
Wilhelmus H.I.M. Drinkenburg ${ }^{a} \quad$ Abdallah Ahnaou $^{a} \quad$ Gé S.F. Ruigt ${ }^{b}$ \\ a Janssen Research \& Development, A Division of Janssen Pharmaceutica NV, Beerse, Belgium; ${ }^{b}$ Clinical Consultancy for \\ Neuroscience Drug Development, Oss, The Netherlands
}

\section{Key Words}

Electroencephalography · Pharmaco-EEG · Pharmaco-sleep EEG · Animal models - Translational research - Drug discovery and development

\begin{abstract}
Current research on the effects of pharmacological agents on human neurophysiology finds its roots in animal research, which is also reflected in contemporary animal pharmacoelectroencephalography ( $p$-EEG) applications. The contributions, present value and translational appreciation of animal $p$-EEG-based applications are strongly interlinked with progress in recording and neuroscience analysis methodology. After the pioneering years in the late 19th and early 20th century, animal p-EEG research flourished in the pharmaceutical industry in the early 1980s. However, around the turn of the millennium the emergence of structurally and functionally revealing imaging techniques and the increasing application of molecular biology caused a temporary reduction in the use of EEG as a window into the brain for the prediction of drug efficacy. Today, animal p-EEG is applied again for its biomarker potential - extensive databases of $p$-EEG and polysomnography studies in rats and mice hold EEG signa-
\end{abstract}

tures of a broad collection of psychoactive reference and test compounds. A multitude of functional EEG measures has been investigated, ranging from simple spectral power and sleep-wake parameters to advanced neuronal connectivity and plasticity parameters. Compared to clinical p-EEG studies, where the level of vigilance can be well controlled, changes in sleep-waking behaviour are generally a prominent confounding variable in animal $p$-EEG studies and need to be dealt with. Contributions of rodent pharmaco-sleep EEG research are outlined to illustrate the value and limitations of such preclinical p-EEG data for pharmacodynamic and chronopharmacological drug profiling. Contemporary applications of $p$-EEG and pharmaco-sleep EEG recordings in animals provide a common and relatively inexpensive window into the functional brain early in the preclinical and clinical development of psychoactive drugs in comparison to other brain imaging techniques. They provide information on the impact of drugs on arousal and sleep architecture, assessing their neuropharmacological characteristics in vivo, including central exposure and information on kinetics. In view of the clear disadvantages as well as advantages of animal $p$-EEG as compared to clinical p-EEG, general statements about the usefulness of EEG as a biomarker to demonstrate the translatability of $p$-EEG effects should be made

\section{KARGER 125}

(c) 2016 S. Karger AG, Base

0302-282X/16/0724-0139\$39.50/0 
with caution, however, because they depend on the particular EEG or sleep parameter that is being studied. The contribution of animal $p$-EEG studies to the translational characterisation of centrally active drugs can be furthered by adherence to guidelines for methodological standardisation, which are presently under construction by the International Pharmaco-EEG Society (IPEG).

(c) 2016 S. Karger AG, Basel

\section{Historical Introduction}

The present paper complements papers on human pharmaco-electroencephalography (p-EEG) in this IPEG special issue with a historical introduction on contemporary animal p-EEG research. Instead of giving a comprehensive review of the effects of drugs on EEG and EEGdefined sleep in animal research per se, it provides an extensive overview of the past and present application of especially pharmaco-sleep-wake EEG (p-sleep EEG) in experimental pharmacological research as well as in the drug discovery and development process for psychoactive drugs [see also Drinkenburg et al., this issue, pp. 151-164]. Contemporary applications of animal p-EEG can be subdivided into spontaneous versus stimulationor event-related EEG. In this paper, the importance of control of the vigilance level and the translational roots of animal p-EEG and p-sleep EEG will be outlined in view of its present restrictions and challenges, emphasising the need for preclinical methodological standardisation [1].

\section{Electroencephalography}

The present translational value, existing issues and the potential for contributions of animal p-EEG within its applications are most adequately understood when a historical perspective on the development of quantitative EEG is appreciated (more detailed accounts can be found elsewhere [2-5]). While the discovery by Luigi Galvani of muscle contractions in frog legs, generated by 'animal electricity', marked the start of electrophysiology in 1780, an electrophysiology-based physiology of the nervous system was first developed in the mid to late 19th century by Carlo Mateucci in Bologna and Emil Du Bois-Rymond in Berlin. Their research culminated in the pioneering work of Julius Bernstein and his membrane theory for the resting and action potential in nerve tissue in 1902, which eventually led to the formulation of Hodgkin and Huxley's Nobel Prize winning model of action potential generation in 1952. Studies of the peripheral nervous system progressed rapidly to the molecular level; however, the electrophysiology of the brain remained more elusive. In 1875 Richard Caton was the first to describe spontaneous electrical current fluctuations in the brain of rabbits and monkeys using two electrodes and a sensitive mirror galvanometer [6]: 'Feeble currents of varying direction pass through the multiplier when the electrodes are placed on two points of the external surface of the skull.' Similar observations were made independently by Vasily Yakovlevich Danilevsky in Kharkiv, Ukraine, who, in 1877, was also the first to describe the effect of electrical brain stimulation in animals in his thesis entitled Investigations into the Physiology of the Brain [7]. Around 1890, Adolf Beck in Krakow used rabbits and dogs to study electrical brain potentials in response to sensory stimulation as well as spontaneous rhythmic fluctuations of brain activity, and described the disappearance of oscillations when the eyes were stimulated with light $[8,9]$.

The term 'electrocerebrogram', which was later modified linguistically by Berger into 'elektrenkephalogramm', was introduced by Pravdich-Neminsky, who also produced the first pictorial demonstration of the EEG in 1912 on the basis of animal recordings of electrical brain activity with a string galvanometer [10]. While conducting animal EEG studies flourished in Eastern Europe, not much EEG research took place in the rest of the world until Hans Berger, who in 1902 had already attempted to record from a dog's brain, started his work on human EEG in 1924 in Jena and produced a series of 14 reports between 1929 and 1938 - 'Über das Elektrenkephalogramm des Menschen' [11]. Among these reports are the first descriptions of alpha and beta waves, sleep EEG and the effect of hypoxia on the human brain, but also the first human p-EEG recordings in 1931 on the alpha power-increasing effects of cocaine, the alpha power reduction after morphine, the generalised power decrease after chloroform and the dose-dependent effects of scopolamine on alpha and beta. In the mid-1930s these findings were replicated by Davis in the USA, by Durup and Fessard in Paris, and by Adrian in Cambridge [12]. From this time onwards electroencephalography bloomed as a part of clinical neurological practice and psychiatry both in Europe and the USA, while the use of superficial EEG recordings in experimental research declined in favour of single neuron studies by the late 1940s. In the next decade, EEG was established as an important diagnostic and guidance instrument for neurosurgery and epileptology, while it also became an essential tool in sleep research due to the pioneering work of Kleitman and Dement [13] in Chicago. 


\section{Pharmaco-Electroencephalography}

In Berlin in the early 1930s, Fischer [14] and Kornmüller [15] were the first scientists to describe the toxic effects of picrotoxin and a number of other convulsive substances, once again firstly on animal EEG. However, apart from some spurious animal p-EEG studies, there was little activity in this research field in the years following. This changed after the late 1950s, when novel antipsychotic (chlorpromazine) and antidepressant (imipramine) drugs were discovered and developed; in a back-translational way, the description of their clinical EEG effects generated much interest for the study of these compounds in animal experimentation. Most of these studies were at that time done in rabbits, cats, dogs and monkeys, and only occasionally in rodents. With the increasing clinical importance of EEG and with the growing number and expanding relevance of pharmaco-therapeutic treatments in psychiatric care during the 1950s and 1960s, attempts were being made to correlate the acute effects of psychotropic drugs on the EEG in healthy volunteers with their clinical efficacy in psychiatric patients [16-25].

The resulting EEG-based orthogonal classification system for psychotropic drugs consisting of a thymoleptic (antidepressant)/psychostimulant axis versus a neuroleptic/anxiolytic axis was shown to have predictive validity when Itil et al. [26] tested the antihistamine mianserin, which was being developed by Organon as an anti-inflammatory drug; the EEG-based classification system, however, classified this drug as an antidepressant. The antidepressant therapeutic potential of mianserin was subsequently confirmed in clinical studies supporting the predictive value of this p-EEG-based classification system. Consequently, the pharmaceutical industries that were active in the development of psychotropic drugs massively implemented and embraced p-EEG, since suitable predictive models in phase I clinical development were lacking in pharmaco-psychiatry. These clinical developments also spurred interest in preclinical, animal p-EEG on the basis of the idea that if p-EEG in phase I human volunteers could be used to predict the psychotropic potential of novel compounds, there might also be value in trying to develop a similar predictive classification system based mainly on the spectral analysis (FFT) of animal p-EEG. Especially since the animal models for psychiatric disorders available at the time lacked face validity and translational potential. p-EEG thus became one of the first translational biomarkers in psychotropic drug development, long before translational medicine was defined as a key process in drug development. Animal p-EEG was relatively cheap when compared to clinical EEG recordings, and

p-EEG Studies in Animals the throughput of compounds was much higher, especially if small rodents were used rather than cats, dogs and monkeys. Thus, animal p-EEG groups emerged in the industry in the early 1980s, exemplified by Ciba-Geigy [27], Duphar [28-30], Janssen Pharmaceutica [31, 32], Organon [33-35], Sandoz [36] and Synthélabo [37]. When clinical p-EEG failed to accurately predict the therapeutic value of a number of compounds (e.g. maroxepine [38]), pharmaceutical companies lost confidence in clinical EEG as a reliable efficacy biomarker, and consequently scaled down or sometimes closed their preclinical EEG facilities. With the parallel emergence of structurally and functionally revealing imaging techniques (i.e. CT, MR, fMRI, PET, SPECT) and the increasing application of molecular biology, the use of EEG as a window into the brain for the prediction of drug efficacy was further reduced in the 1990s. However, during this period p-EEG still proved its biomarker relevance for topics such as (pre)clinical pharmacokinetic-pharmacodynamic (PK-PD) modelling (e.g. the action of benzodiazepines) and the monitoring of the depth of anaesthesia and sleep for the development of anaesthetic and hypnotic drugs $[39,40]$.

Currently, databases of p-EEG and p-sleep studies in rodents have been set up in various academic centres and within pharmaceutical companies, holding EEG signatures ('fingerprints') of a broad collection of psychoactive reference and test compounds. A multitude of functional EEG measures has been investigated mostly in rats and mice, ranging from simple spectral power and sleep-wake parameters to advanced connectivity parameters with highdensity EEG. Reversal studies can also be reliably carried out in animals, comparable to phase I clinical studies; disruption of brain function and concomitant EEG changes can consistently be achieved through pharmacological or behavioural challenges as well as by transgenic manipulation. Such modelled animals are then available for reversal testing with novel test compounds targeting specific brain neurochemistry systems. However, for a valid interpretation of p-EEG effects, in animals, much like in humans, one needs to first appreciate the convoluted modulating relationship between the (p-)EEG and the level of arousal or vigilance, since animal p-EEG poses specific problems in contrast to human p-EEG, in which phase I subjects can be instructed to remain in a relaxed position with their eyes open and without dozing off. Control over behavioural stability is a major challenge in animal p-EEG research, especially since sleep is the most prominent confounding variable in EEG studies. Therefore, attention will first be focused on the incorporation of changes in sleep-waking behaviour and its relevance for animal p-EEG studies. 


\section{Animal p-Sleep EEG}

Similar to eating and drinking, sleep is an essential physiological process in mammalian species, even though its exact function is still not completely understood. The importance of sleep can also be derived from the fact that the processes involved in the generation and maintenance of sleep and waking are well conserved throughout evolution, providing ample opportunities for translational research, not only for sleep physiology, but also for pharmaco-sleep physiology. As such, the pharmacology of sleep and waking is more translational than cortical pEEG per se, since it is the evolution of the cortex in particular that sets man apart from most other mammals. However, the translational study of the neuropharmacology of sleep and sleep-EEG also has its inherent problems since sleep is a fragile state and is modified by a number of internal and external factors. As mentioned earlier, taking into account sleep and waking behaviour is especially important in animal p-EEG studies, since changes in behavioural sleep and waking are the most prominent modulators of the EEG. Therefore, before analysing the effects of a drug on the EEG of free-running animals, the confounding effects of changes in sleep-waking behaviour should be eliminated as much as possible [41]. For vigilance-related changes this can basically be done in two different ways. One may try to entrain animals into a stable state of sustained vigilance, for instance by forced locomotor activity [42] or by training the animals to attend to sensory stimuli and study the effects of drugs on the EEG of such a stable state of vigilance. Alternatively, ethnographical analysis of the behaviour of the animal can be used to segment the EEG into discontinuous segments belonging to different behavioural states and then study the effects of a drug on the more homogeneous EEG for the pooled segments of each of these different states [3335]. This has the added advantage that apart from the effect of a drug on the various behaviour-defined types of EEG, one also obtains the effects of a drug on the ethogram itself [43]. Segmenting the EEG on the basis of sleep and waking behaviour poses a special problem in this context; sleep and especially the different stages of sleep are defined to some extent on the basis of the EEG itself, which means that one cannot study the effects of a drug on sleep-defined EEG in isolation, but always has to take into account the effects of the drug on the hypnogram as well [35]. Drug effects in freely moving animals can be expressed without vigilance control when using a readout that is independent of sleep structure; for instance, the so-called cyclic alternating patterns [44], which indicate rhythmically organised phasic events and arousals over the different stages of sleep, were used by Depoortere et al. [45] as an independent descriptor of drug effects in the rat.

Sleep is evolutionarily well conserved, which also means that similar sleep stages can be distinguished in non-human, mammalian sleep as in man [46, 47]. Using polysomnography (at least 2 EEG electrodes, an EMG electrode and a movement sensor), rapid eye movement (REM) sleep can be reliably distinguished in all mammals as a state of muscle atonia combined with low-amplitude EEG, whereas waking is also characterised by low-amplitude EEG but the muscle tone is much higher. While some research groups qualify the rest of sleep as one unitary non-REM sleep stage, many others discriminate three, more translational non-REM sleep stages, i.e. deep slow-wave sleep, light sleep as the transition from waking to deep slow-wave sleep, and a transition state between deep slow-wave sleep and REM sleep, named intermediate state or pre-REM sleep [33, 34, 48, 49].

Some species differences in the EEG appearance of mammalian sleep do exist: the occurrence of phasic events during sleep is an example of differences in mammalian sleep behaviour. Ponto-geniculo-occipital (PGO) waves are characteristically observed during feline REM sleep, but such waves are limited to the pons and do not propagate to the geniculate nucleus in rodents [50]. Furthermore, rodents lack K-complexes, which are typical for light sleep in humans, while rodents do show sleep spindles during light sleep in a similar way to humans. The translation of p-sleep EEG effects, not only from animal to man, but also from species to species, should be critically assessed because valid translation is not only important from a biomarker perspective or as an early readout of desired therapeutic effects (e.g. hypnotic activity), but also as an early marker of unwanted side effects - the use of many (psycho-)therapeutics is associated with sleep disturbances and sedation.

A drug-induced change in EEG-defined sleep patterns may not necessarily mean that the drug affects the core system of sleep regulation. A drug may affect the slowwave or theta rhythm generator without affecting the basic neuroanatomical systems involved in deep sleep and REM sleep, respectively. By the same token, one cannot always tell whether a drug changes the hypnogram because it affects the underlying mechanisms of sleep and waking or because it affects one of the classification parameters of the sleep classifier, such as a specific effect on the EEG of a sleep state which is part of the classification rules (e.g. delta or theta power affecting slow-wave sleep 
and REM sleep, respectively). An automatic sleep classifier may be advantageous over manual classification in this regard, since it will consistently make the same 'error'. Finally, since an animal can only be in one stage at a certain moment in time, a drug positively affecting the occurrence of one stage automatically reduces the occurrence of other sleep/waking states, thereby posing the question of which effects are primary and which ones are secondary. A drug may for instance reduce REM sleep by either increasing muscle tone, increasing waking without movement, increasing arousability or interfere with the activity of the brainstem REM-on or REM-off cells. This exemplifies the relevance of behavioural monitoring as part of polysomnography when studying the central effects of a drug. This may be the background for the observation that several compounds (e.g. 5-HT2A antagonists) have been shown to increase slow-wave sleep in animals and man [51,52] without improving subjective sleep quality. Some sleep stages are characterised and classified by the presence of phasic events, such as K-complexes and spindles for light sleep and rapid eye movements for REM sleep. Compounds affecting such phasic events will impact the scoring of these stages without necessarily changing the occurrence or quality of these specific sleep states. The same can be argued for essential non-EEG determinants of sleep stages, such as the muscle atonia of REM sleep, while the effect of a drug on such variables may still be used as a good translational biomarker for pharmacological activity. In some cases the specific drug effects can even lead to dissociation between the effect of the drug on overt behaviour and its effect on EEG or EEGdefined sleep and waking. Benzodiazepines are a classical example of this phenomenon as they increase beta power, which is a characteristic effect of conscious waking, whilst overtly producing sleep [53]. Behavioural sleep with an activated EEG pattern can also be found for some anaesthetics. On the other hand, scopolamine and other anticholinergics can produce slow waves in the EEG while the animals are perfectly awake [54].

General statements about the usefulness of EEG as a biomarker to demonstrate the translatability of drug-induced EEG effects should therefore be made with caution, as it depends first and foremost on the particular EEG/ sleep parameter that is being studied. It is obvious that drug effects on animal PGO waves will be difficult to translate, since - although PGO waves have also been described in man - such waves are best observed with intracranial electrodes, which are outside the scope of clinical p-EEG. Anatomical differences are the prime reason that drug effects on theta rhythms, which are characteristic for

p-EEG Studies in Animals rodent waking and REM sleep, cannot be translated to effects on scalp REM sleep EEG in humans, since the theta of rodent REM sleep and waking is generated primarily by the hippocampus [55], which, due to the limited thickness of the cortex, is easily picked up by epidural or scalp EEG electrodes. Theta rhythms are also observed in human cortical EEG, albeit with a somewhat lower frequency (4-7 Hz instead of 6-10 Hz in rodents) and are of cortical origin [101]. The slow waves of slow-wave sleep on the other hand are generated by slow membrane potential oscillations in thalamocortical neurons not only in humans, but also in rodents and other mammalian species [56]. Drug effects on the slow waves of slow-wave sleep are therefore similar between animal and man. The same holds true for sleep spindles, which are comparable between species with respect to their basic physiological mechanisms and their neuropharmacological modulation [57]. By contrast, drug effects on sleep-waking behaviour are generally well translatable between preclinical species and from animal to man, since the neurobiological and neuropharmacological mechanisms involved in the generation of sleep, REM sleep and waking are highly conserved during mammalian evolution, as indicated before.

\section{Chrono-Pharmacology}

Chrono-pharmacological aspects, i.e. the timing of drug administration in the circadian vigilance cycle, are also relevant for the recording of animal p-sleep EEG effects, because many of these studies are performed in rodents, which are nocturnal animals in contrast to other species commonly used for preclinical p-sleep EEG studies. Often a reversed day-night cycle is employed to make it easier to administer the drugs during the active phase of the rodent circadian pattern. Secondly, and more importantly, one needs to consider that the effect of a given drug is dependent on the timing of drug dosing in the circadian cycle. Hypnotics are given before bedtime, since the desired effect is sleep induction and/or sleep maintenance, which is a target effect during the sleep period, but an untoward effect during the waking period. By the same token, antidepressants are given at night or in the morning to overcome the sedative, respectively activating side effects of specific drugs, although one cannot always overcome these side effects, especially if the half-life of a drug is long in comparison to the sleeping period, resulting in hangover effects. However, it is important to note that the efficacy of hypnotics and anaesthetics in terms of 
sedation and sleep induction differs depending on when the drugs are being administered in the circadian cycle, for instance. Such chrono-pharmacodynamics is not only important, but the pharmacokinetics of a drug can also vary, depending on the time of drug dosing [58]. This means that for translational studies drugs need to be administered during the same circadian phase. Another relevant chrono-pharmacological question is whether the p-EEG effects of a drug are translatable and consistent over the various sleep and waking states, independent of its effects on sleep structure. For most drugs, the p-EEG effects are generally similar across the circadian cycle when corrected for the sleep/waking state, be it that the size of the effect may differ depending on sleep stage. There are notable exceptions for drug effect on phasic events, which are restricted to specific sleep states, or drug effects on EEG parameters used for sleep classification. Finally, especially for p-sleep studies, the consistency of effects with multiple or chronic dosing is to be considered in view of the development of tolerance and sensitisation. Not only with multiple dosing, but also with single dosing, it is advisable to record for sufficiently long periods compared to the half-life of a drug, enabling potential rebound effects to be detected on sleep and sleep-defined EEG.

\section{p-Sleep as a Tool for Drug Profiling}

A comprehensive overview of drug effects on animal sleep per se is beyond the scope of the present paper, but much of the basic neurochemical mechanisms involved in sleep-waking behaviour and its regulation have been revealed through animal p-EEG studies. Apart from the use of pharmacological tools to study basic sleep mechanisms, the modulation of sleep/waking by synthetic compounds for drug profiling, i.e. the characterisation of new chemical entities and their potential therapeutic scope for drug development in the pharmaceutical industry, has also frequently been used. Drug profiling using EEG-defined sleep in animals was initiated in the 1970s in an attempt to mimic the success of clinical drug profiling in healthy volunteers using drug effects on vigilance-controlled EEG. As it is difficult to control vigilance in animals, one may study the effects of drugs on waking epochs in freely moving animals after sleep-wake classification with the added advantage of obtaining information concerning the drug effects on sleep-waking behaviour. Using this paradigm, compounds can easily be profiled around the activation-sedation or stimulant-hypnotic axis. Stimulants can be discerned if a motor component is studied (which is relevant for the discrimination of active waking from passive waking). Sedatives can be discriminated from hypnotics if non-REM sleep is divided into light sleep and slow-wave sleep. Such work in rodents is highly translational to what is observed in healthy volunteers.

Further psychotropic properties have been claimed on the basis of alterations of p-sleep, e.g. REM suppression for antidepressants. This may be a relevant characteristic since depressed patients often have shortened REM sleep latencies, a longer time spent in REM and an increased REM intensity, suggesting a disinhibition of REM sleep. Antidepressants suppress REM sleep both in man and in various animal species, with only a few exceptions, which may be related to the fact that many antidepressants directly or indirectly facilitate serotonergic and noradrenergic transmission, which inhibit the activity of REM-on cells. To date, it is still heavily debated whether the decreased REM sleep is an essential feature of the therapeutic effect of antidepressants or whether it is an epiphenomenon of the pharmacological effect of the majority of the current antidepressant drugs. The major limitation of existing antidepressant therapies is their delayed onset of antidepressant action. Rapid-acting interventions such as sleep deprivation provided promising neuroplastic mechanisms for implementing novel rapid-onset treatment strategies. Clinical trials found that a single subanaesthetic dose of ketamine induces a rapid (within $2 \mathrm{~h}$ ) and sustained (1-2 weeks) antidepressant effect in treatment-resistant patients with major depression [59]. Like sleep deprivation, ketamine enhances slow-wave activity (1-4 $\mathrm{Hz}$ ) during non-REM and neurotrophins, such as brainderived neurotrophic factor (BDNF), which are central and peripheral surrogate biomarkers of synaptic plasticity $[60,61]$. Current research efforts of glutamatergic transmission indicate that blockade of the NMDA receptor neurotransmission exerts its initial rapid antidepressant properties via a prolonged change in glutamatergic signalling downstream by increasing the activation of the AMPA receptor mTOR pathway. This leads to activitydependent release of BDNF and critical local neuronal circuits converge via enhanced synaptic plasticity and neuronal synchronisation $[62,63]$. Thus, the increase in sleep EEG slow waves appears to be a marker of the acute increase in BDNF and rapid antidepressant effects in clinical and preclinical studies, whereas improved sleep quality is associated with an extended mood response $[64,65]$.

With respect to other psychotropic drug classes, the p-sleep profiles of anxiolytics and antipsychotics also 
group together in a discriminant analysis and the resultant classifier has been used to successfully predict the activity of novel compounds. The dysfunction of hypocretin/orexin neurons has been implicated in the neurological disorder of narcolepsy [66]. Narcolepsy is characterised by excessive daytime sleepiness, cataplexy and a direct onset of REM sleep. The histaminergic $\left(\mathrm{H}_{3}\right)$ receptor garnered a great deal of interest from the pharmaceutical industry to circumvent the orexin defect by its waking properties. Several histamine $\mathrm{H}_{3}$ receptor antagonists are in clinical development not only for their stimulant and nootropic effects in treatments for neurodegenerative conditions, but also for the treatment of narcolepsy and cognitive deficits due to sleep deprivation. In rats, the time-course, wake-promoting effect of $\mathrm{H}_{3}$ receptor antagonists was less dramatic than the effects of the psychostimulants amphetamine and modafinil [67]. In orexindeficient mice, the $\mathrm{H}_{3}$ antagonist GSK189254 promoted waking and reduced narcoleptic episodes [68]. In healthy men, sleep deprivation was associated with enhancements in delta and theta activity and reductions in alpha and beta activity, whereas the $\mathrm{H}_{3}$ receptor antagonist MK-0249 and modafinil reduced delta and theta activity and enhanced alpha and beta activity [69].

Pharmacological therapy specifically targeting insomnia requires defined pharmacodynamic timing [70]. The GABA-A receptor modulators eszopiclone and zolpidem are widely used to help induce and maintain sleep. Ideal therapeutics of insomnia will, unlike most of the conventional therapies with long half-lives and undesirable mechanisms of action related to adverse effects on other central nervous systems, promote sleep throughout the resting period, maintain normal sleep architecture, and will be devoid of residual drowsiness upon awakening. In the last few years, orexin (hypocretin) receptor antagonism has been shown to be an effective mechanism of promoting somnolence while avoiding residual somnolence during subsequent waking periods when exposures drop to subthreshold receptor occupancy levels prior to the awake period [71-74]. The distribution of target receptors may have important clinical implications in terms of their specificity to desired sleep effects with reduced concerns of off-target effects. Orexin receptors have a more focused distribution compared to the broader distribution of GABA receptors and their concomitant more diverse actions. While both eszopiclone and zolpidem significantly increase slow-wave sleep and disrupt EEG power spectra during non-REM sleep, DORA-22, a dual Orexin 1 and Orexin2 receptor antagonist, promotes somnolence without altering the neuronal network EEG activity observed during sleep $[75,76]$. Supported by preclinical animal p-sleep EEG findings, novel selective orexin-2 antagonists have recently been proposed for clinical testing in primary insomnia [77]. Other hypnotic medications with a shorter duration of action than many traditional benzodiazepines and potentially less risk of tolerance and abuse have also been explored; ramelteon, for example, is a novel $\mathrm{MT}_{1}$ and $\mathrm{MT}_{2}$ melatonergic agonist that was effective in promoting sleep in experimental animals such as rats, cats and monkeys [78].

Consequently, other target pathways and potential novel drug treatments are being studied for their implication in sleep and circadian rhythmicity disorders, anxiety and depression, and in cognitive disturbances using preclinical p-EEG and p-sleep EEG. The central activity of ligands acting at 5HT7, mGluR2, mGluR5, mGluR7 and $\mathrm{MCH} 1$ has been characterised in rodents: inhibition of REM sleep occurrence was observed with 5HT7 antagonists [79-81], mGuR2 agonist and positive allosteric modulators (PAMs) $[82,83]$, and with mGluR7 PAMs [84]. While mGluR2 antagonists and negative allosteric modulators (NAMs) and mGluR5 PAMs exhibit arousalpromoting properties [85-87], mGluR5 NAMs consolidated deep sleep time and cortical delta activity in preclinical as well as clinical studies [85, 88, 89]. Lastly, $\mathrm{MCH} 1$ antagonists decreased deep sleep without homeostatic recovery sleep [48].

The use of animal p-EEG effects during EEG-defined sleep for the prediction of their potential therapeutic scope and efficacy has thus been shown to be a tool of which the validity depends on the specific therapeutic area and which needs careful interpretation in view of its limitations, as outlined above. The value of animal p-EEG for pharmacodynamic and pharmacokinetic drug profiling appears to be much more general.

\section{Translational Considerations of Animal p-EEG Applications}

Differences in cortical development across the evolutionary tree impact on the differences of what is 'seen' by superficial EEG electrodes between animals, including humans. Source localisation of EEG effects in animals is more difficult in most species compared to humans due to the smaller size of the brain, which is also more embedded in the skull, making it more difficult to use a 3D EEG imaging methodology such as LORETA. However, a new spatial mapping technique for modelling large-scale neuronal networks in mouse brains equivalent to human 
neuroimaging has been recently developed [90-92]. A polyimide-based array of 32 or 40 EEG microelectrodes was implemented to detect the location of the sources underlying EEG activation of depth brain structure by optogenetics or epileptic seizure loci in mice, which opens a new avenue of linking human brain mapping with aberrant molecular neuronal processes and circuits in animal models of diseases.

There are also clear advantages of animal p-EEG compared to clinical EEG studies apart from the already mentioned higher throughput of animal p-EEG in drug development. Epidural electrodes are standard, eliminating skull and superficial muscle artefacts. The reduced cortical thickness gives a better resolution of the activity of midbrain structures, which can also be monitored more easily by intracerebral electrodes. Intracerebral cannulas provide means for local (e.g. intracerebroventricular) administration of drugs or large molecules that do not readily cross the blood brain barrier. Lastly, the possibility of combining p-EEG with behavioural analysis or novel methodologies (e.g. optogenetics; calcium imaging) provides unique neuroscientific research opportunities. Notwithstanding the differences with clinical applications, animal p-EEG has excellent (pre)clinical biomarker properties, being continuous, objective, repeatable, reproducible, sensitive, relatively inexpensive and widely available.

In the past decade preclinical EEG has gained strength as a biomarker of the pharmacological activity of centrally active drugs, i.e. for target engagement. One of the best examples is the characterisation and analysis of the EEG effects of benzodiazepines in rat and man. By studying the PK-PD relationships of a range of benzodiazepines with respect to their effects on the EEG beta power, it was observed that there is an excellent translation of receptor affinity at the BZ receptor, as measured from in vitro binding experiments, to the in vivo potency of the same compounds, as derived from rat EEG [93]. Using such advanced mechanism-based PK-PD modelling, the in vivo potency and intrinsic efficacy for novel GABAergic compounds could be predicted [94]. While there are such common p-EEG effects for large groups of drugs, it should also be mentioned that small pharmacological differences may have a major impact on the EEG. This is exemplified by gaboxadol, a GABA receptor agonist that acts as an agonist at extrasynaptic, heteromultimeric GABA receptor ionophores by interacting at the junction of the alpha4 and beta subunits, whereas classical benzodiazepines act at the alpha1-gamma2 subunit interface of synaptic benzodiazepine/GABA receptors [95]. Both compounds have hypnotic properties in rat and man, but benzodiaz- epines increase beta power and reduce theta power in the sleep EEG, whereas gaboxadol increases delta and theta power without an effect on the beta band $[96,97]$.

While there is translational consistency from rodent to man regarding the benzodiazepine-induced beta power increase or the opioid-induced increase in delta power, translatability is not a universal phenomenon for all pEEG effects. 5HT1A partial agonists, for instance, produce a clear theta increase in rodents, whereas they are associated with a theta reduction in humans, probably because the origin of superficial theta in rodent and man is different, as already mentioned above. Both these latter effects can be used for PK-PD modelling and the PK-PD models are translational from rodent to man, suggesting that even if the $\mathrm{p}$-EEG profiles in rat and man are different, one can still use the preclinical p-EEG effects to predict the clinical behaviour of such drugs in phase I trials.

\section{Methodological Standardisation}

In the preceding paragraphs attention has been focused on the impact of sleep-waking behaviour and timing of drug dosing in animal p-EEG studies, but there are numerous other relevant variables that can affect the outcome of animal p-(sleep) EEG studies, which may be obvious, but which are not always adequately mentioned in publications and which may contribute to the many discrepancies often observed in study results for a particular drug. Such variables relate, amongst others, to the subject of study (animal species/strain - large strain differences have for instance been observed in the occurrence of sleep spindles between rat strains), age (sleep structure in animals is strongly influenced by age, as it is in humans), living conditions (circadian light intensity, ambient temperature, feeding, social vs. individual housing, handling and other potential stress factors), recording conditions (placement of recording electrodes, grounding, reference, cable vs. telemetric recordings, novelty of the recording environment, i.e. home cage vs. experimental cage, light/ temperature/feeding/background noise during recording, video monitoring for behavioural control and interpretation of aberrant EEG findings, movement detection), study design (sex, menstrual cycle, route of administration, inclusion of placebo and/or reference drugs, blinding, definition of baseline, cross-over vs. parallel designs, acute vs. chronic dosing, power calculations), data capture (recording bandwidth, sampling frequency, filtering), signal analysis (artefact rejection, sleep classification algorithms, spectral analysis procedures), the classification al- 
gorithms being employed for visual or automatic sleep analysis, and finally the definition and calculation of relevant p-sleep (sleep parameters, phasic events) and p-EEG endpoints (frequency, amplitude, EEG power including definition of frequency bands and time bins), and the statistical procedures used to isolate and describe the drug effect ( $Z$ scores, $t$ statistics, ANOVA, normalisation procedures, use of historical data, correction for multiple comparisons, statistical mapping). All these elements may in a variable manner and degree affect the outcome of animal p-EEG studies and may hinder comparisons between different studies of a particular drug. Thus, it is imperative to standardise the variables mentioned above as much as possible between experiments that are to be compared or at least describe such variables in an adequate, standardised manner. Secondly, it is essential to have an appropriate database at one's disposal to compare how variable the effects of a specific drug are within a drug class as well as over drug classes. To date, in contrast to clinical p-(sleep) EEG $[98,99]$, there are no general recording or analysis principles in animal p-EEG and p-sleep EEG, which makes it difficult to compare drug effects between laboratories. Since most labs have already build up a consistent, homogeneous database of p-EEG effects it is a real challenge to define such principles, as most labs want to stick to their own standards. However, for the same reasons it is imperative that global guidelines for animal recordings and global databases of p-sleep EEG findings are developed in order to validly compare experimental findings between laboratories.
In conclusion, the present applications of p-EEG and p-sleep EEG recordings, in comparison to other brain-imaging techniques like MEG and MRI, which are difficult to apply in animals due to restraint requirements, or PET, which is expensive and requires the availability of appropriate radioligands, provide a common and relatively inexpensive window into the living brain early in the preclinical and clinical development of psychotropic drugs. They provide information on the impact of drugs on arousal and sleep architecture, characterising their neuropharmacological characteristics in vivo, including the relevant question of central exposure and due to the high temporal resolution of p-EEG also elaborate information on kinetics (onset, peak effect time, duration of action).

The p-EEG is thus thought to have significant potential as a translatable, intermediate biomarker of central pharmacodynamic activity and eventually in particular cases as an efficacy marker. However, its full potential could not yet be realised due to the lack of methodology standardisation, especially between academia and industry research, rendering data pooling and meta-analyses flawed and the assessment of translatability problematic [100]. Therefore, this review paper essentially forms a prequel to novel IPEG guidelines for animal p-EEG and animal p-sleep EEG studies. ${ }^{1}$

1 Such guidelines are presently being prepared de novo as a follow-up to
the IPEG human guidelines which have already appeared [98, 99]: with this
paper the IPEG would also like to invite people who think they can further contribute to the formulation of such guidelines to contact the first author.

\section{References}

1 Drinkenburg WH: Electroencephalography and pharmaco-electroencephalography; in Stolerman IP, Price LH (eds): Encyclopedia of Psychopharmacology, ed 2. Berlin, Springer, 2015, pp 592-602.

2 Fink M: A selected bibliography of electroencephalography in human psychopharmacology, 1951-1962. Electroenceph Clin Neurophysiol 1964;23:1-68.

3 Finger S: Origins of Neuroscience: A History of Explorations in Brain Function. New York, Oxford University Press, 1994.

4 Niedermeyer, E: Historical aspects; in Niedermeyer R, Lopes da Silva F (eds): Electroencephalography: Basic Principles, Clinical Applications and Related Fields. Philadelphia, Lippincott Williams and Wilkins, 2005, pp $1-15$.
5 Sanei S: Adaptive Processing of Brain Signals. Hoboken, Wiley, 2013, pp 1-5.

6 Caton R: The electric currents of the brain. $\mathrm{Br}$ Med J 1875;2:278.

7 Eckert K, Maurer N, Lang J: Praxis der evozierten Potentiale: SEP - AEP - MEP - VEP, ed 2. Darmstadt, Steinkopff, 2005.

8 Coenen A, Zayachkivska O, Bilski R: In the footsteps of Beck: the desynchronisation of the electroencephalogram. Electroenceph Clin Neurophysiol 1998;106:330-335.

-9 Coenen A, Zayachkivska O: Adolf Beck: a pioneer in electroencephalography in between Richard Caton and Hans Berger. Adv Cogn Psychol 2013;9:216-221.

10 Brazier MAB: A History of the Electrical Activity of the Brain: The First Half-Century. London, Pitman, 1961.
11 Berger H: Hans Berger on the electroencephalogram of man: the fourteen original reports on the human electroencephalogram (Gloor $\mathrm{P}$, suppl ed). Electroenceph Clin Neurophysiol 1969;28(suppl):1-350.

12 Adrian ED, Matthews BHC: The interpretation of potential waves in the cortex. J Physiol 1934;81:440-471.

13 Dement WC: History of sleep physiology and medicine; in Kryger MH, Roth T, Dement WC (eds): Principles and Practice of Sleep Medicine, ed 4. Philadelphia, Elsevier Saunders, 2005, pp 1-12.

14 Fischer MH: Elektrobiologische Auswirkungen von Krampfgiften am Zentralnervensystem. Med Klin 1933;29:15-19.

15 Kornmüller AE: Der Mechanismus des epileptischen Anfalles auf Grund bioelektrischer Untersuchungen am Zentralnervensystem. Fortschr Neurol Psychiat 1935;7:391-400, 414-432. 
16 Fink M: Quantitative electroencephalography in human psychopharmacology, II: drug patterns; in Glaser G (ed): EEG and Behavior. New York, Basic Books, 1963, pp 177-179.

17 Fink M: EEG classification of psychoactive compounds in man: review and theory of behavioral association; in Efron D, Cole JO, Levine J, Wittenborn JR (eds): Psychopharmacology: A Review of Progress, 1957-1967. Washington, USGPO, 1968, pp 497-507.

18 Fink M: EEG and human psychopharmacology. Ann Rev Pharmacol 1969;9:241-258.

19 Fink M, Itil T: EEG and human psychopharmacology, IV: clinical antidepressants; in Efron F, Cole JO, Levine J, Wittenborn JR (eds): Psychopharmacology: A Review of Progress, 1957-1967. Washington, USGPO, 1969, pp 671-682.

20 Itil TM: Quantitative pharmaco-electroencephalography; in Itil TM (ed): Psychotropic Drugs and the Human EEG. Basel, Karger, 1974, pp 43-75.

21 Herrmann WM, Fichte K, Itil T, Kubicki S: Development of a classification rule for four clinical therapeutic psychotropic drug classes with EEG power spectrum variables of human volunteers. Pharmakopsychiatrie 1979;12: 20-34.

22 Matejcek M: Latest advances in pharmacoelectroencephalography. Pharmakopsych Neuro Psychopharm 1979;12:1-245.

23 Herrmann WM: Electroencephalography in Drug Research. Stuttgart, Fischer, 1982.

-24 Saletu B, Anderer P, Saletu-Zyhlarz GM, Arnold $\mathrm{O}$, Pascual-Marqui RD: Classification and evaluation of the pharmacodynamics of psychotropic drugs by single-lead pharmacoEEG, EEG mapping and tomography (LORETA). Methods Find Exp Clin Pharmacol 2002 24(suppl C):97-120.

25 Gevins A, Smith ME, McEvoy LK: Tracking cognitive pharmacodynamics of psychoactive substances with combinations of behavioral and neurophysiological measures. Neuropsychopharmacology 2002;26:27-39.

26 Itil TM, Polvan N, Hsu W: Clinical and EEG effects of GB-94, a tetracyclic antidepressant: EEG model in the discovery of a new psychotropic drug. Curr Ther Res 1972;14:395-413.

27 Glatt A, Duerst T, Mueller B, Demieville H: EEG evaluation of drug effects in the rat. Neuropsychobiology 1983;9:163-166.

28 Krijzer F, van der Molen R, van Oorschot R, Vollmer F: Effects of antidepressants on the EEG of the rat. Neuropsychobiology 1983;9: 167-173.

29 Krijzer F, van der Molen R: Classification of psychotropic drugs by rat EEG analysis: learning set development. Neuropsychobiology 1986;16:205-214.

30 Krijzer FN, van der Molen R: Classification of psychotropic drugs by rat EEG analysis: the anxiolytic profile in comparison to the antidepressant and neuroleptic profile. Neuropsychobiology 1987; 18:51-56.
31 Wauquier A: Drug effects on sleep-wakefulness patterns in dogs. Neuropsychobiology 1983;10:60-64

32 Dugovic C, Wauquier A: 5-HT2 receptors could be primarily involved in the regulation of slow-wave sleep in the rat. Eur J Pharmacol 1987;137:145-146.

33 Ruigt GS, van Proosdij JN, van Delft AM: A large scale, high resolution, automated system for rat sleep staging. I. Methodology and technical aspects. Electroencephalogr Clin Neurophysiol 1989;73:52-63.

34 Ruigt GS, van Proosdij JN, van Wezenbeek LA: A large scale, high resolution, automated system for rat sleep staging. II. Validation and application. Electroencephalogr Clin Neurophysiol 1989;73:64-71.

- 35 Ruigt GS, Engelen S, Gerrits A, Verbon F: Computer-based prediction of psychotropic drug classes based on a discriminant analysis of drug effects on rat sleep. Neuropsychobiology 1993;28:138-153.

36 Kleinlogel H, Burki HR: Effects of the selective 5-hydroxytryptamine uptake inhibitors paroxetine and zimeldine on EEG sleep and waking stages in the rat. Neuropsychobiology 1987;17:206-212

-37 Depoortere H, Decobert M, Honoré L: Drug effects on the EEG of various species of laboratory animals. Neuropsychobiology 1983;9: 244-249.

38 Herrmann WM, Schärer E, Wendt G, DeliniStula A: Pharmaco-EEG profile of maroxepine: third example to discuss the predictive value of pharmaco-electroencephalography in early human pharmacological evaluations of psychoactive drugs. Pharmacopsychiatry 1991;24:214-224

39 Vijn PC, Sneyd JR: I.v. anaesthesia and EEG burst suppression in rats: bolus injections and closed-loop infusions. Br J Anaesth 1998;81: 415-421.

40 Drinkenburg WH, Ahnaou A: The use of pharmaco-electroencephalography in preclinical models in drug discovery; in Drinkenburg E, Ruigt H, Jobert M (eds): Essentials and Applications of EEG Research in Preclinical and Clinical Pharmacology. Berlin, IPEG, 2004, pp 131-148.

41 Beerling W, Koolhaas JM, Ahnaou A, Bouwknecht JA, de Boer SF, Meerlo P, Drinkenburg WH: Physiological and hormonal responses to novelty exposure in rats are mainly related to ongoing behavioral activity. Physiol Behav 2011;103:412-420.

42 Krijzer F, Koopman P, Olivier B: Classification of psychotropic drugs based on pharmaco-electrocorticographic studies in vigilancecontrolled rats. Neuropsychobiology 1993;28: 122-137.

43 van Lier H, Drinkenburg WHIM, van Eeten YJW, Coenen AML: Effects of diazepam and zolpidem on EEG beta frequencies are behavior-specific in rats. Neuropharmacology 2004;47:163-174.

44 Terzano MG, Parrino L: Origin and Significance of the Cyclic Alternating Pattern (CAP). Sleep Med Rev 2000;4:101-123.
45 Depoortere H, Françon D, Granger P, Terzano MG: Evaluation of the stability and quality of sleep using Hjorth's descriptors. Physiol Behav 1993;54:785-793.

46 Zepelin H, Siegel JM, Tobler I: Mammalian sleep; in Kryger MH, Roth T, Dement WC (eds): Principles and Practice of Sleep Medicine, ed 4. Philadelphia, Elsevier Saunders, 2005, pp 91-100.

47 Siegel JM: Clues to the functions of mammalian sleep. Nature 2005;437:1264-1271.

48 Ahnaou A, Drinkenburg WH, Bouwknecht JA, Alcazar J, Steckler T, Dautzenberg FM: Blocking melanin-concentrating hormone $\mathrm{MCH} 1$ receptor affects rat sleep-wake architecture. Eur J Pharmacol 2008;579:177-188.

49 Gottesmann C, Gandolfo G, Arnaud C, Gauthier P: The intermediate stage and paradoxical sleep in the rat: influence of three generations of hypnotics. Eur J Neurosci 1998;10: 409-414.

50 Datta S: Cellular basis of pontine ponto-geniculo-occipital wave generation and modulation. Cell Mol Neurobiol 1997;17:341-365.

51 Idzikowski C, Mills FJ, James RJ: A dose-response study examining the effects of ritanserin on human slow wave sleep. Br J Clin Pharmacol 1991;31:193-196.

52 Morairty SR, Hedley L, Flores J, Martin R, Kilduff TS: Selective 5HT2A and 5HT6 receptor antagonists promote sleep in rats. Sleep 2008;31:34-44

53 Coenen AM, van Luijtelaar EL: Pharmacological dissociation of EEG and behavior: a basic problem in sleep-wake classification. Sleep 1991; 14:464-465.

54 Wikler A: Pharmacological dissociation of behaviour and EEG 'sleep patterns' in dogs: morphine, $\mathrm{N}$-allylnormorphine, and atropine. Proc Soc Exp Biol NY 1952;79:261-265.

55 Sullivan D, Mizuseki K, Sorgi A, Buzsáki G: Comparison of sleep spindles and theta oscillations in the hippocampus. J Neurosci 2014; 34:662-674.

56 Bazhenov M, Timofeev I, Steriade M, Sejnowski, TJ: Model of thalamocortical slowwave sleep oscillations and transitions to activated states. J Neurosci 2002;22:8691-8704

57 Steriade M: The corticothalamic system in sleep. Front Biosci 2003;8:d878-d899.

58 Lemmer B: Chronopharmacokinetics: implications for drug treatment. J Pharm Pharmacol 1999;51:887-890.

- 59 Diazgranados N, Ibrahim L, Brutsche NE, Newberg A, Kronstein P, Khalife S, Kammerer WA, Quezado Z, Luckenbaugh DA, Salvadore G, Machado-Vieira R, Manji HK, Zarate CA Jr: A randomized add-on trial of an $\mathrm{N}$ methyl-D-aspartate antagonist in treatmentresistant bipolar depression. Arch Gen Psychiat 2010;67:793-802

60 Faraguna U, Vyazovskiy VV, Nelson AB, Tononi G, Cirelli C: A causal role for brainderived neurotrophic factor in the homeostatic regulation of sleep. J Neurosci 2008;28: 4088-4095. 
61 Tononi G, Cirelli C: Sleep function and synaptic homeostasis. Sleep Med Rev 2006;10: 49-62.

-62 Duman RS, Aghajanian GK: Synaptic dysfunction in depression: potential therapeutic targets. Science 2012;338:68-72.

63 Li N, Lee B, Liu RJ, Banasr M, Dwyer JM, Iwata M, Li XY, Aghajanian G, Duman RS: mTOR-dependent synapse formation underlies the rapid antidepressant effects of NMDA antagonists. Science 2010;329:959-964.

64 Autry AE, Adachi M, Nosyreva E, Na ES, Los MF, Cheng PF, Kavalali ET, Monteggia LM: NMDA receptor blockade at rest triggers rapid behavioural antidepressant responses. Nature 2011;475:91-95.

- 65 Duncan WC, Sarasso S, Ferrarelli F, Selter J, Riedner BA, Hejazi NS, Yuan P, Brutsche N, Manji HK, Tononi G, Zarate CA: Concomitant BDNF and sleep slow wave changes indicate ketamine-induced plasticity in major depressive disorder. Int J Neuropsychopharmacol 2013;16:301-311.

- 66 de la Herrán-Arita AK, García-García F: Current and emerging options for the drug treatment of narcolepsy. Drugs 2013;73:1771-1781.

67 Griebel G, Decobert M, Jacquet A, Beeské S: Awakening properties of newly discovered highly selective $\mathrm{H}_{3}$ receptor antagonists in rats. Behav Brain Res 2012;232:416-420.

- 68 Guo RX, Anaclet C, Roberts JC, Parmentier R, Zhang M, Guidon G, Buda C, Sastre JP, Feng JQ, Franco P, Brown SH, Upton N, Medhurst AD, Lin JS: Differential effects of acute and repeat dosing with the $\mathrm{H}_{3}$ antagonist GSK189254 on the sleep-wake cycle and narcoleptic episodes in Ox-/- mice. Br J Pharmacol 2009;157:104-117.

-69 James LM, Iannone R, Palcza J, Renger JJ, Calder N, Cerchio K, Gottesdiener K, Hargreaves R, Murphy MG, Boyle J, Dijk DJ: Effect of a novel histamine subtype-3 receptor inverse agonist and modafinil on EEG power spectra during sleep deprivation and recovery sleep in male volunteers. Psychopharmacology 2011;215:643-653.

70 Roehrs T, Roth T: Insomnia pharmacotherapy. Neurotherapeutics 2012;9:728-738.

-71 Brisbare-Roch C, Dingemanse J, Koberstein R, Hoever P, Aissaoui H, Flores S, Mueller C, Nayler O, van Gerven J, De Haas SL, Hess P, Qiu CB, Buchmann S, Scherz M, Weller T, Fischli W, Clozel M, Jenck F: Promotion of sleep by targeting the orexin system in rats, dogs and humans. Nat Med 2007;13:150-155.

-72 Herring WJ, Snyder E, Budd K, Hutzelmann J, Snavely D, Liu K, Lines C, Roth T, Michelson $\mathrm{D}$ : Orexin receptor antagonism for treatment of insomnia: a randomized clinical trial of suvorexant. Neurology 2012;79:2265-2274.

-73 Gotter AL, Winrow CJ, Brunner J, Garson SL, Fox SV, Binns J, Harrell CM, Cui D, Yee KL, Stiteler M, Stevens J, Savitz A, Tannenbaum PL, Tye SJ, McDonald T, Yao L, Kuduk SD, Uslaner J, Coleman PJ, Renger JJ: The duration of sleep promoting efficacy by dual orexin receptor antagonists is dependent upon re- ceptor occupancy threshold. BMC Neurosci 2013;14:90.

74 Winrow CJ, Gotter AL, Cox CD, Tannenbaum PL, Garson SL, Doran SM, Breslin MJ, Schreier JD, Fox SV, Harrell CM, Stevens J, Reiss DR, Cui D, Coleman PJ, Renger JJ: Pharmacological characterization of MK-6096 - a dual orexin receptor antagonist for insomnia. Neuropharmacology 2012;62:978-987.

75 Bettica P, Squassante L, Groeger JA, Gennery B, Winsky-Sommerer R, Dijk DJ: Differential effects of a dual orexin receptor antagonist (SB-649868) and zolpidem on sleep initiation and consolidation, SWS, REM sleep, and EEG power spectra in a model of situational insomnia. Neuropsychopharmacology 2012;37: 1224-1233.

76 Fox SV, Gotter AL, Tye SJ, Garson SL, Savitz AT, Uslaner JM, Brunner JI, Tannenbaum PL, McDonald TP, Hodgson R, Yao L, Bowlby MR, Kuduk SD, Coleman PJ, Hargreaves R, Winrow CJ, Renger JJ: Quantitative electroencephalography within sleep/wake states differentiates GABAA modulators eszopiclone and zolpidem from dual orexin receptor antagonists in rats. Neuropsychopharmacology 2013;38:2401-2408.

77 Letavic MA, Bonaventure P, Carruthers NI, Dugovic C, Koudriakova T, Lord B, Lovenberg TW, Ly KS, Mani NS, Nepomuceno D, Pippel DJ, Rizzolio M, Shelton JE, Shah CR, Shireman B, Young LK, Yun S: Novel octahydropyrrolo[3,4-c]pyrroles are selective orexin-2 antagonists: SAR leading to a clinical candidate. J Med Chem 2015;58:5620-5636.

78 Srinivasan V, Pandi-Perumal SR, Trahkt I, Spence DW, Poeggeler B, Hardeland R, Cardinali DP: Melatonin and melatonergic drugs on sleep: possible mechanisms of action. Int J Neurosci 2009;119:821-846.

79 Ahnaou A, Huysmans H, Jacobs T, Drinkenburg WH: Cortical EEG oscillations and network connectivity as efficacy indices for assessing drugs with cognition enhancing potential. Neuropharmacology 2014;86:362-377.

-80 Di Pilato P, Niso M, Adriani W, Romano E, Travaglini D, Berardi F, Colabufo NA, Perrone R, Laviola G, Lacivita E, Leopoldo M: Selective agonists for serotonin $7\left(5-\mathrm{HT}_{7}\right)$ receptor and their applications in preclinical models: an overview. Rev Neurosci 2014;25: 401-415.

81 Hedlund PB: The 5- $\mathrm{HT}_{7}$ receptor and disorders of the nervous system: an overview. Psychopharmacology 2009;206:345-354.

82 Ahnaou A, Dautzenberg FM, Geys H, Imogai H, Gibelin A, Moechars D, Steckler T, Drinkenburg WH: Modulation of group II metabotropic glutamate receptor $\left(\mathrm{mGlu}_{2}\right)$ elicits common changes in rat and mice sleepwake architecture. Eur J Pharmacol 2009;603: 62-72.

83 Hikichi H, Hiyoshi T, Marumo T, Tomishima Y, Kaku A, Iida I, Urabe H, Tamita T, Yasuhara A, Karasawa J, Chaki S: Antipsychotic profiles of TASP0443294, a novel and orally active positive allosteric modulator of metabotropic glutamate 2 receptor. J Pharmacol Sci 2015;127:352-361.

84 Cavas M, Scesa G, Navarro JF: Positive allosteric modulation of mGlu7 receptors by AMN082 affects sleep and wakefulness in the rat. Pharmacol Biochem Behav 2013;103: 756-763.

85 Ahnaou A, Langlois X, Steckler T, BartolomeNebreda JM, Drinkenburg WH: Negative versus positive allosteric modulation of metabotropic glutamate receptors (mGluR5): indices for potential pro-cognitive drug properties based on EEG network oscillations and sleepwake organization in rats. Psychopharmacology 2015;232:1107-1122.

86 Gilmour G, Broad LM, Wafford KA, Britton T, Colvin EM, Fivush A, Gastambide F, Getman B, Heinz BA, McCarthy AP, Prieto L, Shanks E, Smith JW, Taboada L, Edgar DM, Tricklebank MD: In vitro characterisation of the novel positive allosteric modulators of the mGlu $_{5}$ receptor, LSN2463359 and LSN2814617, and their effects on sleep architecture and operant responding in the rat. Neuropharmacology 2013;64:224-239.

87 Loomis S, McCarthy A, Baxter C, Kellett DO, Edgar DM, Tricklebank M, Gilmour G: Distinct pro-vigilant profile induced in rats by the mGluR5 potentiator LSN2814617. Psychopharmacology 2015;232:3977-3989.

88 Harvey BD, Siok CJ, Kiss T, Volfson D, Grimwood S, Shaffer CL, Hajós M: Neurophysiological signals as potential translatable biomarkers for modulation of metabotropic glutamate 5 receptors. Neuropharmacology 2013;75:19-30.

89 Lindemann L, Porter RH, Scharf SH, Kuennecke B, Bruns A, von Kienlin M, Harrison AC, Paehler A, Funk C, Gloge A, Schneider M, Parrott NJ, Polonchuk L, Niederhauser U, Morairty SR, Kilduff TS, Vieira E, Kolczewski S, Wichmann J, Hartung T, Honer M, Borroni E, Moreau JL, Prinssen E, Spooren W, Wettstein JG, Jaeschke G: Pharmacology of basimglurant (RO4917523, RG7090), a unique metabotropic glutamate receptor 5 negative allosteric modulator in clinical development for depression. J Pharmacol Exp Ther 2015;353:213-233.

90 Mégevand P, Quairiaux C, Lascano AM, Kiss JZ, Michel CM: A mouse model for studying large-scale neuronal networks using EEG mapping techniques. Neuroimage 2008;42: 591-602.

-91 Choi JH, Koch KP, Poppendieck W, Lee M, Shin HS: High resolution electroencephalography in freely moving mice. J Neurophysiol 2010;104:1825-1834.

92 Lee C, Oostenveld R, Lee SH, Kim LH, Sung $\mathrm{H}$, Choi JH: Dipole source localization of mouse electroencephalogram using the Fieldtrip toolbox. PLoS One 2013;14:e79442.

-93 Mandema JW, Danhof M: Electroencephalogram effect measures and relationships between pharmacokinetics and pharmacodynamics of centrally acting drugs. Clin Pharmacokinet 1992;23:191-215. 
94 Visser SA, Wolters FL, Gubbens-Stibbe JM, Tukker E, van der Graaf PH, Peletier LA, Danhof M: Mechanism-based pharmacokinetic/pharmacodynamic modeling of the electroencephalogram effects of GABAA receptor modulators: in vitro-in vivo correlations. J Pharmacol Exp Ther 2003;304:88101.

95 Chandra D, Jia F, Liang J, Peng Z, Suryanarayanan A, Werner DF, Spigelman I, Houser CR, Olsen RW, Harrison NL, Homanics GE: GABAA receptor alpha 4 subunits mediate extrasynaptic inhibition in thalamus and dentate gyrus and the action of gaboxadol. Proc Natl Acad Sci USA 2006;103:15230-15235.
96 Lancel M, Faulhaber J: The GABAA agonist THIP (gaboxadol) increases non-REM sleep and enhances delta activity in the rat. Neuroreport 1996;7:2241-2245.

97 Walsh JK, Deacon S, Dijk DJ, Lundahl J: The selective extrasynaptic GABAA agonist, gaboxadol, improves traditional hypnotic efficacy measures and enhances slow wave activity in a model of transient insomnia. Sleep 2007;30:593-602.

98 Jobert M, Wilson FJ, Ruigt GSF, Brunovsky M, Prichep LS, Drinkenburg WHIM: Guidelines for the recording and evaluation of pharmaco-EEG data in man - International Pharmaco-EEG Society (IPEG). Neuropsychobiology 2012;66:201-220.
99 Jobert M, Wilson FJ, Roth T, Ruigt GSF, Anderer P, Drinkenburg WHIM: Guidelines for the recording and evaluation of pharmaco-sleep studies in man - International Pharmaco-EEG Society (IPEG). Neuropsychobiology 2013;67:127-167.

100 Wilson FJ, Leiser SC, Ivarsson M, Christensen SR, Bastlund JF: Can pharmaco-electroencephalography help improve survival of central nervous system drugs in early clinical development? Drug Discov Today 2014; 19:282-288.

101 Mitchell DJ, McNaughton N, Flanagan D, Kirk IJ: Frontal-midline theta from the perspective of hippocampal 'theta'. Prog Neurobiol 2008; 86: 156-185. 